\title{
DIE CHRISTLICHE MARTYRIUMSIDEE *
}

Die Absicht dieses Artikels ist keineswegs eine Darstellung der ganzen christlichen Lehre über das Martyrium. Es geht in ihm eher um das Fassen im dynamischen (Entwicklungs-) Aspekt ihrer wesentlichen Züge auf der Basis der ganzen Literatur des 20. Jahrhunderts. Der Verfasser bemüht sich nicht nur den Begriff des Martyriums zu entwerfen, sondern auch die Versuche seiner Verweiterung darzustellen, die Quellen, von denen er abzuleiten ist, vorzulegen und den Ort, den er in der Kirche einnimmt, festzustellen. Dieses Studium dagegen unternimmt keine theologischen Auslegungen des Martyriums, die dieses sei es als Bluttaufe (Patristik), sei es als den höchsten Akt der Tapferkeit und Liebe (Scholastik, Vaticanum II), sei es auch als Enthüllung des christlichen Wesens des Todes (K. Rahner), verstehen.

\section{IDEE}

Zuerst wird der Begriff des Martyriums untersucht, den die Kirche als ihren eigenen betrachtet. Nach der Beschreibung seiner Hauptelemente werden besprochen: geistiges Martyrium und das Martyrium der im Krieg gefallenen Soldaten, als Versuch einer Verbreitung der eigentlichen Martyriumsidee.

\section{Begriff des Martyriums}

Es scheint, dass Origenes in seinem Kommentar zum Johannes-Evangelium gut den Sinn des christlichen Martyriums aufgefasst hat. Seiner Meinung nach jeder, der der Wahrheit Zeugnis gibt, abgesehen davon ob

* Vgl. in dieser Hinsicht die an der Gregorianischen Universität in Rom am 1.2.1967 verteidigte und im Frühling 1968 veröffentlichte Dissertation des Verfassers: A. $\mathrm{Kubiś,} \mathrm{La} \mathrm{théologie} \mathrm{du} \mathrm{martyre} \mathrm{au} \mathrm{vingtième} \mathrm{siècle} \mathrm{(Pontificia} \mathrm{Uni-}$ versitas Gregoriana, Facultas Theologica), Roma 1968, besonders 88-172; Ders. Chrześcijańska idea męczeństwa, in: Analecta Cracoviensia, 2 (1970) 303-328; I. Gordon, De conceptu theologico canonico martyrii ratione habita tum doctrinae traditionalis, tum recentiorum opinionum ac problematum, in: Ius Popoli Dei. Miscellanea in honorem Raymundi Bidagor (I), Roma 1972, 486-521. 
er das durch Worte, Taten oder in irgendwelcher Weise beweist, mit Recht ein Zeuge genannt werden kann. Es ist zu einem Brauch bei den Brüdern geworden - dank der Bewunderung für diejenigen, die bis zum Tod für Wahrheit oder Unschuld gekämpft haben - als Zeugen (Märtyrer) im vollen Sinn dieses Wortes ausschliesslich diese Menschen zu nennen, die vergiessend ihr Blut ein Zeugnis dem Geheimnis des Glaubens gegeben haben. Der Heiland dennoch sieht jeden, der von seiner Lehre Zeugnis gibt, als Zeugen an ${ }^{1}$.

Die Meinungen der zeitgenössischen Autoren über das Martyrium dekken sich ganz mit diesen Worten. Zum Beispiel R. Reitzenstein schreibt über das Martyrium des hl. Polykarp und über das in der ganzen Patristik dargestellte Martyrium so: den Menschen, der für Christus gestorben ist, hat man martys tou Christou oder martys tou theou genannt; der Tod wurde als martyria oder martyrion angesehen; das gestorben sein hat man als martyresai bezeichnet ${ }^{2}$. Ähnliche Ansicht vertritt H. Leclercq. Anführend acht Fragmente aus der Beschreibung des Martyriums des hl. Polykarp behauptet er, dass man den Sinn des Wortes Märtyrer als Bezeichnung des für den Glauben erlittenen Todes nicht mehr in Zweifel ziehen darf. In diesem Sinn ist der Terminus Martyrium in den Wortschatz der Christen hineingegangen. Verwenden ihn auch Schriftsteller, derer Werke nur den Lokalkirchen bekannt sind ${ }^{3}$. Im Verständnis von F. Paschke gehören zu den Märtyrern Heilige, die den Glauben an Christus durch den Tod bescheinigt haben ${ }^{4}$. Keinen anderen Sinn hat auch

1 Origéne, Commentaire sur saint Jean II, 210: SourcesChr 120, 351. Aber schon „Clément d'Alexandrie (vers 216) prélude pour ainsi dire à la théologie du martyre. Bien qu'il veuille montrer qu'il existe un martyre spirituel, consistant dans une vie pure, néanmoins l'analogie qu'il établit entre le chrétien parfait et le martyr montre assez qu'au sens propre la mort est regardée comme inhérente au concept de martyre", E. Hoc e d e z, Le concept de martyr, in: Nouvelle revue théologique, 55 (1928) 90.

2 R. Reitzenstein, Bemerkungen zur Martyrienliteratur. I. Die Bezeichnung Märtyrer, in: Nachrichten von der königlichen Gesellschaft der Wissenschaften zu Göttingen. Philologisch-historische Klasse, 3 (1916) 421. - Vgl. ebd., 418-419; $442-445$.

${ }^{3}$ H. L e clercq, Saint, in: Dictionnaire d'archéollogie chrétienme et de liturgie, 15 (1950) 389. - Vgl. Th. Baumeister, Die Anfänge der Theologie des Martyriums, Münster 1980.

${ }^{4} \mathrm{~F}$. P a s chke, Märtyrer, in: Die Religion in Geschichte und Gegenwart, 4 (31960) 588. - Vgl. F. K a t te n bu s c h, Der Märtyrertitel, in: Zeitschrift für die neutestamentliche Wissenschaft und die Kunde der älteren Kirche, 4 (1903) 111. - A. Kranich, Ist Kriegertod Märtyrertod?, in: Das ermländische Pastoralblatt, (1917) 2-3. - M. R a ckl, Ist der Tod fürs Vaterland ein Martyrium? (Separatabdruck aus der christlichen Schule 8. Jahrgang, 1917, Heft 4), Eichstätt 1917, 9-14. - P. Alla rd, Dix leçons sur le martyre, Paris 71930, 7. Ders., Martyre, in: Dictionnaire apologétique de la foi catholique, 3 (1926) 337. - P. Corss e n, Begriff und Wesen des Märtyrers in der alten Kirche, in: Neue Jahrbücher für das klassische Altertum und Pädagogik, 35 (1915) 481; 384; 487; 492. Ders., Uber die Bildung und Bedeutung der Komposita Pseudoprofetes, Pseudomantis, Pseudomartys. Eine Erwiderung, in: Sokrates, 72 (1918) 113. - G. K r üg e r, Zur Frage der Entstehung des Märtyrertitels, in: Zeitschrift für die neutestamentliche Wis- 
die Übersetzung des Wortes Märtyrer in den Sprachen des Nahen Ostens. Vom Anfang an - bemerkt in dieser Hinsicht P. Peeters - als nur der Märtyrer in die ältesten Sprachen des Ostens eingegangen ist, hat er dort immer einen für den Glauben sterbenden Menschen und nichts mehr bezeichnet 5 .

Hieraus ergibt sich, dass zwei Faktoren das Wesen des Martyriums in christlicher Auffassung bilden, und zwar: das öffentlich Christus gegebene Zeugnis ${ }^{6}$ und der bewusst und freiwilig angenommener Tod, um es zu bestätigen ${ }^{7}$. Dabei sind sie in gleicher Weise notwendig, d.h. ohne sie gibt es einfach keine christliche Martyriumsidee.

Trotz allem darf man von der entscheidenden Rolle des Inhaltes des durch die Märtyrer gegebenen Zeugnisses nicht vergessen. Denn es sind bekannt Worte des hl. Augustinus über dieses Problem: „Ursache, und nicht Strafe macht aus den Menschen Märtyrer" 8. Christliche Märtyrer

senschaft und die Kunde der älteren Kirche, 17 (1916) 268. - F. Dornseiff, Der Märtyrer: Name und Bewertung, in: Archiv für Religionswissenschaft, 22 (1923-1924) 149. - E. Peters o n, Martirio e martire, in: Enciclopedia cattolica, 8 (1952) 234-236. - M. S chm a us, Katholische Dogmatik, Bd. IV/1: Die Lehre von den Sakramenten, München ${ }^{5} 1957,174-175$.

$5 \mathrm{P}$. P e e ters, Les traditions orientales du mot martyr. Note complémentaire à l'article précédent, in: Analecta Bollandiana, 39 (1921) 53-54. - M. L o t-Borodine ist für die Existenz der doktrinellen Unterschiede betreffs des Martyriums bei den Griechen und in der Westkirche: Appendice. Les deux aspects iconographiques du martyre chrétien en Orient et en Occident, in: Irénikon, 27 (1957) 167. - Vgl. ebd. 168. — Es wird gut noch eine originelle russische Martyriumsauffassung zu signalisieren. „Die alten hagiograpischen Dokumente zeugen für das Bestehen eines neuen Märtyrer-Ideals im religiösen Bewusstsein des russischen Volkes. Nicht nur der Christ, der seinen Glauben vor dem Richterstuhl der Heiden ader der Ketzer bis zum Toide bekennit, gilt sls Märtyrer, sondern jeder, der unschulldig leildet unid wiiderstianidlos den Toid auf sich nimmit, um so Chrisitius 'gleilchförmig' zu werden. Als „Sstrasstoterpez” gilt, wer eine Passion erduldet, wer durch seine Sanftmut und Unterwerfung, seinen Sieg über die Liebe zum Leben und zur Welt dem Erlöser ähnlich wird in der Liebe zu Gott und den Menschen. Ganz wie die Kinder von Bethlehem bekennt er das Fleischgewordene Wort 'non loquendo sed moriendo'", T. Kolog riwow, Das andere Russland. Versuch einer Darstellung des Wesens und der Eigenart russischer Heiligkeit, München 1958, 32--33.

6 E. Peterson, Zeuge der Wahrheit (Die Offenbarung und der Märtyrer), in: Ders., Theologische Traktate, München 1951, 188-189. - Vgl. W. S c h öll g e n, Aktuelle Moralprobleme, Düsseldorf 1955, 469.

$7 \mathrm{~W}$. Hell $\mathrm{mans}$, Wertschätzung des Martyriums als eines Rechtfertigungsmittels in der altchristlichen Kirche bis zum Anfange des vierten Jahrhunderts (Inaugural-Disseration), Breslau 1912, 4-6. - Vgl. J. Pohle, Soldatentod und Märtyrertod. Eine neue Untersuchung mit besonderer Berücksichtigung der Lehre des hl. Thomas von Aquin. Zugleich ein Beitrag zur Theorie des Martyriums, Paderborn 1918, 3-15; 16-25; 51-80. - H. H ed d e, Martyre, in: Dictionnaire de théologie catholique, 10 (1928) $222 ; 225 ; 229$. - P. L u mbreras, De fortitudine et temperantia (Praelectiones scholasticae in secundam partem D. Thomae, 11), Romae 193924 28. - J. E. S h e r m a n, The Nature of Martyrdom. A Dogmatic and Moral Analysis to the Teaching of St. Thomas Aquinas (A Dissertation), Paterson 1942, 118-134.

${ }_{8}$ "Martyres non facit poena sed causa", S. Augustinus, Enarrationes in Ps. 34: PL 36, 340. - Mit anderen Worten, „nicht die Todesart und die Todesqual, sonidern der objekitive Toidessanlass und die subjekitive Absilcht slinid die ausschlaggebenden Momente des echten Martyriums". Pohle, Soldatentod und 
sollen Jesus von Nazareth, den Gekreuzigten und Auferstandenen, den weiter Lebenden, der ,wiederkommt zu richten die Lebendigen und die Toten", bezeugen. Folgerichtig bezeugen sie die Offenbarung Gottes im Wort, das Fleisch geworden ist, d.h. den zweiten Bund, die Erfüllung des Gesetzes (telos), das Ziel und Krönung des ersten ist ${ }^{9}$. Daher Jesus Christus, nicht nur der historische Jesus, sondern auch der gegenwärtig Lebendige und zur Rechten des Vaters sitzende Herr, „machtvoll eingesetzt als Sohn Gottes" (Röm 1,4) bildet den Gegenstand des durch die Märtyrer abgelegten Zeugnisses. Der Märtyrer gibt das Leben nicht nur für die Lehre Jesu, sondern auch für seine Person, mit der er sich durch viele Bande der Frömmigkeit und der Liebe verbunden fühlt ${ }^{10}$.

Ausserdem ist es noch an die durch Theologen allgemein angenommene Meinung des hl. Thomas von Aquin zu erinnern, dass man für Christus sowohl dann leidet, wenn es wegen des Glaubens an Ihn, als auch dann, wenn es wegen der aus Liebe zu Ihm vollbrachten guten Taten, geschieht 11. Das Christus gegebene Zeugnis fasst daher sowohl Glaubens - als auch Moralangelegenheiten um ${ }^{12}$. Demnach kann nicht als Märtyrer derjenige genannt werden, der irgendwelcher Wahrheit Zeugnis gibt, sondern nur der der Gottes Wahrheit Zeugnis Gebende - sonst käme man zum Unsinn. Man müsste dann als Märtyrer, z. B. einen Menschen anerkennen, der für eine geometrische Wahrheit oder eine philosophische Theorie gestorben ist ${ }^{13}$. Andererseits nicht nur der Glaube selbst kann Ursache des Martyriums werden, sondern auch jede mit Gott eine Beziehung habende Tugend, weil endlich die Werke der Tugenden, insofern sie Gott betreffen, eine gewisse Art des Glaubensbekenntnisses sind. Denn der Glaube belehrt, was Gott von den Menschen verlangt und wie Er ihre Taten belohnt ${ }^{14}$.

Märtyrertod, 117. - Corsen, Begrif und Wesen des Märtyrers in der altchristlichen Kirche, 481. - $\mathrm{R}$ a ckl, Ist der Tod fürs Vaterland ein Martyrium?, 20-24. - Deswegen kann man nicht mit E. E sking einig werden, der behauptet, dass in der katholischen Martyriumsauffassung der Tod wichtiger als das Glaubensbekenntnis ist. Das Martyrium als theologisch-exegetisches Problem, in: In memoriam Ernst Lohmeyer, hrsg. W. Schmauch, Stuttgart 1951, 225.

$9 \mathrm{H}$. W. Surkau, Martyrien in jüdischer und frïhchristlicher Zeit (Forschungen zur Religion und Literatur des A. und des N. Testaments, 54), Göttingen 1938, 139-140. - Vgl. Rackl, Ist der Tod fürs Vaterland ein Martyrium?, 10-12. - E. Barbotin, Le témoignage spirituel (Thèse pour le doctorat en théologie), Paris 1964, 248-249.

$10 \mathrm{M}$. Lod s, Confesseurs et martyrs. Successeurs des prophètes dans l'Église des trois premiers siècles (Cahiers théologiques, 41), Neuchâtel-Paris 1958, 22-24. Vgl. Pohle, Soldatentod und Märtyrertod, 27.

$11 \mathrm{~S}$. Thomas, Super Epistolam ad Romanos lectura, c. 8. 1ec. 7, in: S. Thomas Aquinas, Super Epistolas S. Pauli lectura (ed. VIII revisa cura P. Raphaelis Cai), vol. 1 (Taurini-Romae 1953), 131.

${ }_{12} \mathrm{P}$ o h le, Soldatentod und Märtyrertod, 31-33.

${ }^{13}$ S. Thomas, Sum. theol., II-II, q. 124, a. 5, ad 2.

$14 \mathrm{~S}$. Thomas, In IV Sent., d. 49, q. 5, a. 3, qla 2, ad 11 u. ad 12 . - Vgl. Hellmanns, Wertschätzung des Martyriums als eines Rechtfertigungsmittels 
Überdies bleiben die das Zeugnis gebende Märtyrer unter dem Einfluss der Wirkung des Heiligen Geistes. Nach der Meinung von M. Viller ist dieser Einfluss ausser allem Zweifel. Normalerweise bleibt er innerlich und geheimnisvoll. Es gibt doch in der Geschichte des christlichen Martyriums Fälle, in denen man ihn in ganzer Pracht erblicken kann ${ }^{15}$. Der Heilige Geist gab ihnen Rat in der Zeit der Probe. Es ist kein Wunder, dass die Gläubigen den Leib der Märtyrer als Wohnung des Heiligen Geistes und sie als Geistesträger angesehen haben ${ }^{\mathbf{1 6}}$.

Nach A. P. Frutaz kann man folglich sagen, dass im heutigen christlichen Sprachgebrauch der Märtyrer derjenige ist, der sein Leben für Christus, d.h. für die zur christlichen Offenbarung gehörende Wirklichkeit oder Warheit (für die Verteidigung des Glaubens, der christlichen Tugend, z. B. der Keuschheit, des Beichtgeheimnisses oder der Rechte und der Einheit der Kirche) geopfert hat und dass diese Idee des mit einer übernatürlichen Kraft unterstützten Blutzeugen der Gottheit Christi und seiner Religion, obwohl sie schon im 2. Jahrhundert präzisiert wurde, dennoch bis heute die einzige Bezeichnung des Martyriums bildet, die von der Kirche als authentisch anerkannt gilt ${ }^{17}$.

Noch mehr, die beschriebene Martyriumsidee stimmt mit derjenigen überein, welche auf den Seiten der Hl. Schrift deutlich hervortritt ${ }^{18}$. Freilich, diese Behauptung bedeutet nicht, dass sich in der Hl. Schrift ein fertiger, in allen Einzelheiten aussgearbeiteter -Martyriumsbegriff befindet. Denn in der Wirklichkeit - bemerkt mit Recht W. Derouaux - der Mensch, der für das Bekenntnis seines Glaubens an die Gottheit Christi das Blut vergiesst, gleichzeitig Zeuge und Held; vollkommener Nachfolger des Meisters, des ersten Màrtyrers, und Opfer, das das Leben für die Sünden darbringt; ein Wunder der übernatürlichen Gnade und ein der Welt

in der altchristlichen Kirche, 5--6. - Kranich, Ist Kriegertod Märtyrertod?, 23-27; 35-36. - P o hle, Soldatentod und Märtyrertod, 26-50; 108-134. Hedde, Martyre, 225-227. - Lumbreras, De fortitudine et temperantia, 23-33. - Sherman, The Nature of Martyrdom, 57-92. - D. Ruiz Bueno, Actas de los mártyres (Bibliateca de autores cristianos, 75). Madrid 1951, 3-67. $15 \mathrm{M}$. Ville r, Les martyrs et l'Esprit, in: Recherches de science religieuse, 14 (1924) $544-551$.

${ }_{16}$ F. J. Dölger, Gladiatorenblut und Märtyrerblut. Eine Szene der Passio Perpetuae in kultur- und religionsgeschichtlicher Beleuchtung, in: Vorträge der Bibliothek Warburg, hrsg. F. SAXL, Leipzig-Berlin 1926, 213. - Vgl. L. C e rfaux, Témoins du Christ (d'après le Livre des Actes), in: Angelicum, 20 (1943) 173-176. - R. Asting, Die Verkündigung des Wortes im Urchristentum. Dargestellt an den Begriffen „Wort Gottes”, „Evangelium” und „Zeugnis”, Stuttgart $1939,705$.

17 A. P. Frutaz, Märtyrer, in: Lexikon für Theologie und Kirche, 7 (21962) $127-129$.

$18 \mathrm{Vg}$. E. Peterson, Apostel und Zeuge Christi. Auslegung des Philipperbriefes, Freiburg i. Br., 1940. - Vgl. H. Strathmann, Martys, in: Theologisches Wörterbuch zum Neuen Testament, 4 (1942) 513-514. - Esking, Das Martyrium als theologisch-exegetisches Problem, 225. - D. Barsotti, Il martirio nella S. Scrittura, in: Humanitas, 10 (1955) 317-326. 
und den Brüdern im Glauben gegebens Beispiel; ein Aủserwählter, der erlöst wird und ein Mitttler bei Gott, ist. Im Lichte dessen, was oben angeführt wurde, ist es vielleicht ein normales, psychologisches Gesetz, dass diese aufeinanderfolgenden Aspekte bezüglich der Martyriumsidee allmählich entdeckt wurden. Diese Tatsache soll uns weder wundern noch beunruhigen ${ }^{19}$.

Deswegen kann man der These von H. F. Campenhausen, die der Kirche eine Missbildung der ursprünglichen, reinen Martyriumsidee vorwirft, nicht Recht geben. Seiner Meinung nach die ursprüngliche, mit der Person Jesu, seinem Kommen, Verkündigung und Tod unlösbar verbundene Martyriumsidee, beginnt nach und nach der Missbildung zu erliegen. Die katholische Kirche hat sie sogar ganz verunstaltet. Erst die Reformation, die Bedeutung des Wortes Gottes aufwertend hat dem Martyrium die gebührende Stelle als dem Zeugnis, das der Verkündigung Christi gegeben wurde, wiederhergestellt ${ }^{20}$. Diese These ist nicht wahr. Denn aus der Tatsache, dass die Kirche allmählich die Fülle ihres Bewusstseins über das Martyrium gewonnen hat, ergibt sich nicht, dass sie auf diesem Weg die ursprüngliche Idee verraten hat. Die Kirche hat nur systematisch die Früchte der Arbeit gesammelt, die man im Laufe der Jahrhunderte geleistet hat.

Die Kirchengeschichte kennt dennoch Versuche der Erweiterung der eigentlichen Martyriumsidee. Im Zusammenhang mit ihnen ist es nötig das Problem ,des geistigen Martyriums” und des „Martyriums” der christlichen Soldaten zu bertrachten ${ }^{21}$. Das erste war schon den Kirchenvätern bekannt, das zweite dagegen wurde mit besonderer Intensität während des 1. Weltkrieges (1914-1918) diskutiert.

\section{Geistiges Martyrium}

Was sollte man unter dem geistigen Martyrium verstehen? ${ }^{22}$ Es geht hier um die Lehre vom doppelten Martyrium, die in der Kirche dank der christlichen Askeze und Predigt entstanden ist ${ }^{23}$. Nun, neben dem blu-

19 W. Derouaux, Rezension des Werkes H. F. von Campenhausen, Die Idee des Martyriums in der alten Kirche, in: Analecta Bollandiana, 55 (1937) 359.

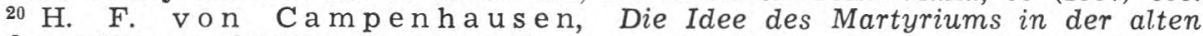
Kirche, Göttingen 21964, 1; 5; 174-175. - Ausser der in der Anm. 19 erwähnten Rezension lohnt sich in dieser Hinsicht zu konsultieren: J. de Ghellinck, Rezension des Werkes v. H. F. von Campenhausen, Die Idee des Martyriums in der alten Kirche, in: Nouvelle revue théologique, 64 (1937) $416-417$.

21 Unter den Theologen wurde auch diskutiert, ob man die hl. Jungfrau Maria, den hl. Joseph, die hl. Unschuldigen Kinder, den guten Schächer am Kreuz und die Persomen, die infolge der Pflege der ansiteckend Kranken gestorben sind, als Märtyrer nennen darf. Vgl. M. R a ckl, Die Anschauung der katholischen Theologen über das Martyrium des Soldatentotes, in: Divus Thomas, 8 (1921) 62-67.

$22 \mathrm{H}$. Hed de spricht vom Martyrium, ,per analogiam”, Martyre, 222.

23 Bei Irländern existierte eine Theorie vom dreifachen Martyrium. Neben dem roten Martyrium, also wirklichen und blutigen Martyrium, hat man Martyrien 
tigen Martyrium derer, die ihr Leben für den Glauben geopfert haben bemerkt M. Viller - gibt es ein unblutiges Martyrium der Gläubigen, die ohne Vorbehalt die Räte des Meisters erfüllen; neben dem einmaligen, das das Opfer darbringt, existiert ein tägliches das ganze Leben hindurch dauerndes Martyrium; neben dem öffentlichen Martyrium, das sich äusserlich unter vielen Augen vollzieht, besteht ein im Tiefen des Bewusstseins verborgenes Martyrium; das Martyrium des Leibes und das Martyrium des Geistes ${ }^{24}$. Diese Doktrin, definitiv durch Gregor den Grossen formuliert, gehört $\mathrm{zu}$ den sehr alten Lehren in der Kirche ${ }^{25}$. Während der ersten drei Jahrhunderte des Christentums sprach man vom ,,vertretbaren" mit der Askeze vergleichenden Martyrium. Im Osten (Klemens v. Alexandrien, Origenes), wie auch im Westen (Tertullian, Cyprianus, Commodianus), hat man das Martyrium mit den unbedingten Anstrengungen fürs Erreichen der Tugend, besonders der Tugend der Keuschheit, verglichen. Die Vorbereitung zum Martyrium, die Begierde des Martyriums, kam fast auf das gleiche, wie das reale und blutige Martyrium ${ }^{26}$.

Als die Verfolgungen beendet waren (313), hat man als geistiges Martyrium vor allem das monastische Leben anerkannt. Alle, die in dieser Zeit von Mönchen sprechen, setzen sie den Märtyrern gleich; - in ihren Augen sind die Mönche Nachfolger der Märtyrer ${ }^{27}$. Daher wagt man keinen Irrtum, wenn man behauptet, dass die christliche patristische Überlieferung das asketische und monastische Leben als Martyrium geschätzt hat ${ }^{28}$.

Nach der Meinung von H. F. Campenhausen die christliche Martyriumsidee hat mit den oben genannten Anschauungen nicht nur ihre Entwicklung beendet, sondern diese bedeuten auch ihre Dekadenz ${ }^{29}$. Es scheint dennoch, dass dieser Standpunkt nicht ganz gerecht ist. Die Idee des

anderer Farben unterscheidet: ein weisses Martyrium, das sehr oft mit der Bewahrung der Keuschheit identifiziert ist und ein grünes Martyrium, das sich in den als Busse für die Sünden unternommenen Abtötungsakten realisiert. Die letzte Gattung des Martyriums ist nur den Irländern bekannt. - L. G o u g a u d, Les conceptions $d u$ martyre chez les Irlandais, in: Revue bénédictine, 24 (1907) 360-374. - Vgl. J. R y a n, Irish Monasticism. Origins and Early Development, London-New York-Toronto 1931, 197-198; 283; 400. - M. Viller, K. Rahner, Aszese und Mystik in der Väterzeit, Freiburg i. Br. 1939, 40.

$24 \mathrm{M}$. Ville r, Le martyre et l'ascèse, in: Revue d'ascétique et de mystique, 6 (1925) 140-141. - Vgl. K u biś, La théologie du martyre au vingtième siècle, 51, Anm. 24.

${ }^{25} \mathrm{~S}$. Gregorius, Hom. 33 in Evangel.: PL 76, 1263. - Vgl. ders., Dial. 3. 26: PL 57, 281. - Vil1 e r, Le martyre et l'ascèse, 141, Anm. 144.

${ }_{26} \mathrm{~V}$ ille r, Le martyre et l'ascèse, 105-115. - F. E. M a 1 on e, The Monk and the Martyr. The Monk as the Successor of the Martyr (A Dissertation), Washington 1950, 1-43.

${ }_{27} \mathrm{~V}$ ill er, Le martyre et l'ascèse, 115-135. - Malone, The Monk and Martyr, 44-143. - U. Ranke-Heinemann, Das frühe Mönchtum. Seine Motive nach den Selbstzeugnissen, Essen 1944, 95-100; 129-143.

${ }_{28}$ A. Stolz, L'ascèse chrétienne, Chevetogne 1948, 123. - Vgl. ebd. 120-143. ${ }^{29} \mathrm{Campenhausen,} \mathrm{Die} \mathrm{Idee} \mathrm{des} \mathrm{Martyriums} \mathrm{in} \mathrm{der} \mathrm{alten} \mathrm{Kirche,} 144$. 
geistigen Martyriums enthaltet ganz gewiss einige für das blutige Martyrium wesentliche Elemente, d.h. für das Martyrium im eigentlichen Sinn dieses Wortes. Denn der wahre Wert des Märtyrers besteht in der restlosen Hingabe im Zeugnis. Und gerade diese restlose Gabe von sich selbst gibt es in dem mit dem Glauben übereinstimmenden christlichen Leben. Um so mehr, da das sehr oft heidnische und mit Permissivismus übersättigte Millieu, in dem die Christen heute leben, verlangt von ihnen die Bezeugung, d.h. das Handeln gegen die Ansichten und üblichen Bràuche. Das fordert sehr oft grosses Opfer. Eben solche Martyriumshaltung durch Liebe ist das Wesen der Lehre des Evangeliums ${ }^{30}$.

\section{Martyrium der im Krieg gefallenen Soldaten}

Der Tod der Soldaten, die auf der Front umkommen, ist ganz bestimmt das höchste Opfer, das ein Mensch darbringen kann. Verdient er aber auch die Benennung Martyrium? Ist es wahr, dass das für die Heimat vergossene Blut gerade so wie das wahre für Christus erlittene Martyrium, die Vergebung der Sünden und sofortigen Zutritt der Seele in den Himmel bewirkt? Mit anderen Worten, kann das Opfer eines christlichen Soldaten vom theologischen Standpunkt aus zur Würde des Martyriums erhoben werden? Die Meinungen der Theologen in dieser Hinsicht sind sehr unterschiedlich ${ }^{31}$.

Die deutschen Theologen, wie M. Rackl ${ }^{32}$, A. Kranich ${ }^{33}$ und J. Pohle ${ }^{34}$ erkennen den Tod der auf dem Felde der Ehre gefallenen Soldaten natürlich unter manchen Bedingungen - als wahres, christliches Martyrium an ${ }^{35}$. Diese Theologen berufen sich auf die Autorität des hl. Thomas von Aquin, der behauptet, dass jedes menschliche Wohl, soviel es eine Beziehung zu Gott hat, die Ursache des Martyriums werden kann ${ }^{36}$.

30 P. Lucien-Marie de Saint-Joseph, Le martyre d'amour, in: Limites de l'humain (Les études carmélitaines), Paris 1953, 339. — Vgl. ebd. 336-338 .

$31 \mathrm{Rack}$, Die Anschauung der katholischen Theologen über das Martyrium des Soldatentodes, 69-76. - A. Kl eber, A Soldier's Death, a Martyrdom?, in: The American Ecclesiastical Review, 111 (1944) 281-290. - D. J. S a u d e r s, The Supernatural Value of a Soldier's Death, in: Theological Studies, 6 (1945) 35-50 .

${ }^{32} \mathrm{Rackl}$, Ist der Tod fürs Vaterland ein Martyrium?, Ders., Die Anschauung der katholischen Theologen über das Martyrium des Soldatentodes, $145-150$.

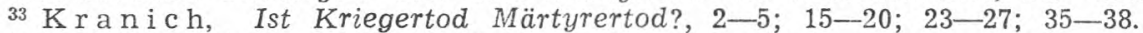

$34 \mathrm{Poh}$ le, Soldatentod und Märtyrertod.

$35 \mathrm{Rackl}$, Die Anchauung der katholischen Theologen über das Martyrium des Soldatentodes, 149-150. Ders., Ist der Tod fürs Vaterland ein Martyrium, 1-9; $24-30 ; 39 ; 40-41$. - Kran i h, Ist Kriegertod Märtyrertod?, 37. - Poh le, Soldatentod und Märtyrertod, 32; 129.

36 S. Thomas, Sum. Theol., II-II, q. 124, a. 5. ad 3. - Es ist doch zu bemerken, dass die Möglichkeit des Martyriums am Kampffeld ablehende Theologen sich auch auf die Autorität des hl. Thomas von Aquin berufen. $\mathrm{K} r$ a $\mathrm{n}$ i $\mathrm{c}$, Ist Kriegertod Märtyrertod?, 18. 
Ihre Ansichten gehen überdies nach der Linie des Urteiles von M. Luther, der nicht nur die auf einem Scheiterhaufen verbrannten Menschen, sondern auch die mit der Waffe in der Hand im Krieg gegen Türken gefallenen Soldaten als Märtyrer proklamiert hat ${ }^{37}$.

In Frankreich hat dieses Problem die Theologen ähnlich interessiert, aber ihre Behauptungen scheinen weniger kategorisch zu sein. A. Michel, präzisierend die Lehre des hl. Thomas von Aquin zu diesem Thema, schreibt, dass die Klugheit des Doktor Angelicus, die sich auf der Klugheit der Kirche gründet, unsere Haltung bestimmen soll. Wenn es für einen Soldaten sogar möglich wäre auf dem Feld der Ehre ein wahrer Märtyrer zu werden, doch scheint diese Möglichkeit für besondere Fälle begrenzt und so bedingt zu sein, dass man sich vor jedem Versuch der Verallgemeinerung hüten soll. Wenn es bei diesem Problem irgendwelche Hoffnung gibt, so ist es nicht nötig diese Hoffnung aus sehr wenig wahrscheinlicher Ähnlichkeit des Soldatentods mit dem christlichen Martyrium, sondern aus sicherer Doktrin von der aussersakramentalen durch den Akt vollkommenen Liebe geschehenden Rechtfertigung zu schöpfen ${ }^{38}$.

Übrigens, grosse Zahl der französisch sprechenden Theologen gibt den auf der Front gefallenen Soldaten den Titel des Martyrers nicht zu. „Der auf dem Kampffeld sterbende Soldat ist kein Märtyrer im exakten und theologischen Sinn - hat Kardinal D. J. Mercier in seinem berühmten Hirtenbrief über den Patriotismus und über das Überdauern zu Weihnachten 1914 geschrieben - weil er mit der Waffe in der Hand stirbt, während sich der Märtyrer der Übermacht der Schinder ohne einen Widerstand zu leisten ergibt. Wenn ihr aber fragt, was man vom ewigen Heil des, um die Ehre der Heimat zu verteidigen und die angegriffene Gerechtigkeit zu rächen, bewussit das Leben hingebenden Helden denken soll, so antworte ich ausser allem Zweifel, dass Christus den Soldatenheldenmut und den christlich angenommenen Tod belohnt und das Heil der Seele des Soldaten sichert" ${ }^{39}$. Kardinal L. Billot ${ }^{40}$, Y. de la Brière ${ }^{41}$, P. Allard 42 sind der gleichen Meinung. Für eine Stellung voll Vorbehalt ist auch zum Ende des 2. Weltkrieges D. J. Saunders, bei einer Diskussion über dieses Problem in den Vereinigten Staaten ${ }^{43}$.

37 E. Sta uffer, Märtyrertheologie und Täuferbewegung, in: Zeitschrift für Kirchengeschichte, 52 (1933) 553.

${ }_{38}$ A. M iche1, La guerre et le martyre d'après saint Thomas d'Aquin, in: Revue pratique d'apologétique, 25 (1917) 82-83.

${ }^{39}$ D. J. M e r cier, Patriotisme et endurance, Paris 1914, 20-21.

$40 \mathrm{Y}$. de $1 \mathrm{a} \mathrm{Br}$ ière, Luttes de l'Église et luttes de la patrie (Troisième série: Luttes présentes de l'Égllise, Août 1914-Décembre 1915), Panis 1916, 361, Anm. 1. - Allard, Martyre, 338 .

${ }_{41} \mathrm{De} 1 \mathrm{a} \mathrm{Brière,} \mathrm{Luttes} \mathrm{de} \mathrm{l'Église} \mathrm{et} \mathrm{luttes} \mathrm{de} \mathrm{la} \mathrm{patrie,} \mathrm{357-376.}$

42 Allard, Martyre, 337-339.

${ }^{43}$ Saunders, The Supernatural Value of a Soldier's Death, 50. 
Das Martyrium der Kreuzfahrer - wie behauptet $\mathrm{H}$. F. von Campenhausen - ist etwas neues und typisch für das Mittelalter ${ }^{44}$. Für H. Doergens die Beimessung des Martyriums den gafallenen Soldaten ist eine Konsequenz der falschen durch den hl. Thomas von Aquin angewandten Methode. Abgesehen von dem aus dem Grund historischen Charakter der M.ärtyrerterminologie nimmt er eine extremistische Position an, d.h. er forscht sie und interpretiert in einer ausschliesslich spekulativen und rationalen Weise. Deswegen kann man eine wahre Martyriumsidee nur bei den Kirchenvätern finden ${ }^{45}$.

$\mathrm{Ob}$ man hier auch mit den Einflüssen der Moslemsreligion oder ganz einfach mit einer Wiederholung der Idee des Islam über den Tod der im heiligen Krieg gegen die Ungläubigen gefallenen Soldaten zu tun hat, wie es F. Dornseiff ${ }^{46}$ möchte, ist sehr zweifelhaft ${ }^{47}$. Jedenfalls die Kirche hat immer die Suggestion der Heiligsprechung der Soldaten wegen ihres Martyrertodes am Kampffeld abgelehnt. Sind sie vor Gott heilig? Das ist ein Geheimnis, dessen Lösung die theologischen Erwägungen und Diskussionen vielleicht niemals geben werden.

\section{URSPRUNG DES MARTYRIUMS}

In den Erwägungen über den Ursprung der christlichen Idee des Martyriums wird es um die Untersuchung der Quellen gehen. Bei diesem Problem besteht eine dreifache Möglichkeit. Diese Idee kann ein ausschliessliches Eigentum des Christentums sein oder kann auch von anderen Religionen, den heidnischen oder dem Jundentum, abgeleitet werden. H. F. von Campenhausen verteidigt die Eigenartigkeit der ursprünglichen christlichen Idee des Martyriums, es gibt aber auch andere Ansichten, die ihre Abhängigkeit sei es von den heidnischen Religionen, sei es vom Judaismus sich zu beweisen bemühen. Es unterliegt keinem Zweifel, dass, was man auch von den erwähnten Behauptungen in ihrer Ganzheit sagen würde, in der christlichen Martyriumsidee man eigenartige Elemente anerkennen muss, besonders ihren christologischen Charakter, der eine besondere Beziehung des Märtyres zu Christus voraussetzt. Eben diese Problematik wird der Gegenstand unserer weiteren Erwägungen.

${ }^{44} \mathrm{C}$ ampenhausen, Die Idee des Martyriums in der alten Kirche, 174-175. Anm. 6.

${ }^{45}$ H. Doergens, Zur Geschichte des Begriffes „Martyr”, in: Der Katholik, 21 (1918) 205-208.

${ }^{46}$ D ornse iff, Der Märtyrer: Name und Bewertung, 151-153.

47 C. Erdmann, Die Entstehung des Kreuzzugsgedankens (Forschungen zur Kirchen- und Geistesgeschichte, 6), Stuttgart 1935, 27-28. - W. B jörkmann, Shahid, in: Handwörterbuch des Islam, Leiden 1941, 663. - H. Dörrie, Märtyrer, in: Die Religion in Geschichte und Gegenwart, 4 ( ${ }^{(31960)} 588 .-\mathrm{B}$ a u m e is t e r, Die Anfänge der Theologie des Martyriums, 307-313. 


\section{Anschauung von H. F. von Campenhausen}

Nach der Meinung von H. F. Campenhausen die Idee des Martyriums verdankt ihren Ursprung dem Christentum ${ }^{48}$, Tatsächlich finden wir sie nicht in anderen Religionen und in anderen Philosophien. So behauptend denkt er an die ursprüngliche Martyriumsidee, d.h. diejenige, die sich in den synoptischen Evangelien und bei hl. Paulus befindet.

Zuerst muss man den hellenischen Einfluss ausschlissen, weil er sich in einem viel späteren Zeitraum und in einem schon verunstalteten Martyriumsbegriff sichtbar macht und zu Beginn des Christentums gibt es ihn nicht. In dieser Auffassung ist der Märtyrer eine Einverleibung und Verkörperung aller Tugenden ${ }^{49}$.

Auch das Alte Testament und der Judaismus kommen hier nicht in Betracht, weil ihr Martyriumsbegriff ganz vom christlichen abweicht. Der jüdische Märtyrer bleibt nur treu dem Gesetz und gehorsam den Gottesgeboten, während das christliche Martyrium im konkreten Befehl der Verkündigung Jesu, d.h. seines Lebens, Predigt und Todes besteht. Der jüdische Märtyrer hat keinen besonderen Auftrag zur Bezeugung der historischen Ereignisse, der im christlichen Martyrium eine entscheidende Bedeutung hat. Besitzen ihn ausschliesslich die Bekenner des Herrn ${ }^{50}$.

Beweise für die Unterstützung seiner Aussage findet H. F. von Campenhausen in der Urgemeinde, d.h. in den synoptischen Evangelien und bei hl. Paulus, weil dort die Verkündigung und das Leiden in einem Zusammenhang bleiben ${ }^{51}$. Durch die Aussendung zur Mission (Math 10) hat Jesus seinen Jüngern die Verkündigung der eschatologischen Botschaft, die er gebracht und deren Zeichen er selbst war, anvertraut. „Geht und verkündet: Das Himmelreich ist nahe” (Math 10, 7). Die Jünger werden dennoch auf viele Hindernisse stossen und werden verfolgt. In dieser Situation sollen sie bis zum Tod treu bleiben. „Fürchtet euch nicht vor denen, die den Leib töten, die Seele aber nicht töten können, sondern fürchtet euch vor dem, der Seele und Leib ins Verderben stürzen kann (Math 10, 28). Nach H. F. von Campenhausen die Worte Christi, wenn man sie im Ganzen nimmt, verlangen nicht den physischen Tod. Sie machen auch keine deutliche Abgrenzung zwischen den Märty-

${ }^{48} \mathrm{Campenhausen,} \mathrm{Die} \mathrm{Idee} \mathrm{des} \mathrm{Martyriums} \mathrm{in} \mathrm{der} \mathrm{alten} \mathrm{Kirche,} \mathrm{1.} \mathrm{-}$ Vgl. H. Koch, Rezension H. F. von Campenhausens, Die Idee des Martyriums in der alten Kirche, in: Theologisches Literaturblatt, 62 (1937) 141-144. - O. C ase1, Altschristliche Liturgie bis auf Konstantin d. Gr., in: Archiv für Liturgiewissenschaft, 1 (1950) 340-345. - Esking, Das Martyrium als theologisch-exegetisches Problem, 229. -156 .

${ }^{49} \mathrm{Campenh}$ a us en, Die Idee des Martyriums in der alten Kirche, 2; 152-

50 Ebd., 2-5.

51 Ebd., 5-20. 
rern und den übrigen Gläubigen, weil alle gesandt sind, alle zusammen zu den Bekennern gehören, die Jesus Christus nicht verraten dürfen ${ }^{52}$. Noch mehr. Die Idee der im Martyrium vorhandenen Kraft, die anzieht und rechtfertigt, ist auch in ihnen abwesend ${ }^{\mathbf{5 3}}$.

Dieselben Ideen - sagt H. F. von Campenhausen - befinden sich bei hl. Paulus, in dessen Lehre es auch noch keinen Martyriumsbegriff im vollen Sinn gibt ${ }^{54}$. Er war vor allem ein Missionar. Die Verkündigung der frohen Botschaft ist für ihn in gewissem Abschnitt des Lebens innerliche Notwendigkeit geworden. „Wenn ich das Evangelium verkündige, kann ich mich deswegen nicht rühmen: denn ein Zwang liegt auf mir. Wehe mir, wenn ich das Evangelium nicht verkündigte" (1 Kor 9, 16). Aus diesem Grund war das ganze Leben de's hl. Paulus ein grosses Martyrium. Durch seine Handlungs- und Verkündigungweise, die im totalen Absterben für sich selbst bestecht, hat er Christus verkündet ${ }^{55}$. Der Tod ist im Denken des hl. Paulus nicht das einzige Mittel der Bezeugung. Ausserdem, obwohl bei ihm die Idee des Todes mit Christus im Zusammenhang mit den durch Verfolgungen herbeigebrachten Leiden bleibt, dennoch hat sie keine Beziehung zum wirklichen Märtyrertod ${ }^{56}$. Kosequent der physische Tod als besondere Form der Bezeugung ist der ursprünglichen den Synoptikern und dem hl. Paulus bekannten Martyriumsidee fremd ${ }^{57}$.

Dennoch scheint es, dass die Anschauung von H. F. von Campenhausen in extenso nicht zu erhalten ist. Denn einerseits muss man den Unterschied zwischen den Märtyrern des Christentums und den Heroen des Altertums hervorheben, andererseits darf man nicht vergessen, dass die christliche Martyriumisidee im Alten Testament und im Judaismus eingewurzelt ist.

\section{Hellenische Möglichkeit}

Es geht hier um das Forschen des Problems, ob das Martyrium dem Heidentum bekannt wurde, oder anders, ob man von Märtyrern der Philosophie sprechen kann.

Der Erste, der die philosophischen Einflüsse auf den christlichen Martyriumsbegriff sich zu zeigen bemüht hat, war J. Geffcken. Seiner Meinung nach die Philospohie des Altertums hat ihre Märtyrer gehabt, z. B. Sokrates, den man so in der heidnischen Literatur bezüglich des Martyriums, als auch in den christlichen „Acta Martyrum” als Beispiel gestellt

52 Ebd., 9; 17-19.

53 Ebd., 7.

${ }^{54}$ Ebd., 10; 12.

55 Ebd., 14.

56 Ebd., 17.

57 Ebd., 20. 
hat ${ }^{58}$. Vor allem aber Epiktet, auch ein Philosoph, war ein Weiser, der sich zum Leiden und sogar zum Tod mit Verachtung verhielt. In seinen „Unterredungen" soll man den Ursprung des Begriffes, das Urbild von des Märtyrers Wesen suchen ${ }^{59}$. Daher sollte man annehmen, dass der stoische Märtyrer ein Vorgänger (Präkursor) des christlichen Märtyrers ist. Daraus zieht J. Geffcken einen einfachen Schluss, dass sich die „Acta Martyrum" der Christen nach den den heidnischen Helden gewidmeten Erzählungen bilden ${ }^{60}$.

Diese Ansicht wurde durch R. Reitzenstein, der im Prinzip die Behauptungen von J. Geffcken wiederholt, entwickelt und erweitert. Nach der Beschreibung einiger mit dem christlichen Martyrium Ähnlichkeit habenden hellenischen Paralellen, bittet R. Reitzenstein nur den Leser sie selbst zu vergleichen und in dieser Weise ähnliche Begriffe entdecken zu können, bei deren Grundlage nicht nur ein gemeinsames Wort, sondern auch dieselbe fundamentale Idee liegt, die die Antwort auf alle einzelne Probleme geben ${ }^{61}$.

Eine ähnliche Unternehmung in dieser Richtung, obwohl dieses nicht in erster Linie sein Ziel war, stellt der Artikel von H. A. Fischel betitelt „Martyr and Prophet” dar ${ }^{62}$. Vorausgesetzt die Möglichkeit gegenseitiger Einflüsse zwischen verschiedenen Religionen im Bereich des römischen Imperiums ${ }^{63}$, erblickt er die Kennzeichen der Änlichkeit zwischen den Propheten und den jüdischen und christlichen Märtyrern einerseits, und den griechischen Helden andererseits ${ }^{64}$. Nach Fischel ausserordentliche Naturphänomene im Moment des Todes des Helden waren ein Kennzeichen des Zornes der Götter. Ziemlich oft sind diese Phänomene durch himmlische Stimmen ersetzt. Etwas ähnliches stellt die plötzliche Strafe, die dem den Märtyrer zu töten befehlenden Imperator begegnet, dar. Nach der Art der griechischen Götter sind sowohl die jüdischen, als auch die christlichen Märytrer schön. Man rühmt auch ihr Alter, Ansehen und sogar schreibt ihnen die Würde und Funktionen der Engel zu ${ }^{65}$.

58 J. Geffcken, Die christlichen Martyrien, in: Hermes, 45 (1910) 493-

59 Ebd., 496.

60 Ebd., 497.

${ }_{61}$ R. Reitzenstein, Historia monachorum und historia lausiaca. Eine Studie zur Geschichte des Mönchtums und der frühchristlichen Begriffe Gnostiker und Pneumatiker (Forschungen zur Religion und Literatur des A. und des N. Testaments, 24), Göttingen 1916, 85-88; 257. Ders., Bemerkungen zur Martyrienliteratur. 1. Die Bezeichnung Märtyrer, 454.

$62 \mathrm{H}$. A. F is c he 1, Martyr and Prophet, in: The Jewish Quarterly Review, 37 (1947) 265-280; 363-386. - Vgl. Asting, Die Verküindigung des Wortes im Urchristentum, 699-705.

${ }_{63} \mathrm{~F}$ i s c h e 1, Martyr and Prophet, 269.

64 Ebd., 382-383.

65 Ebd., 376-382. - Vgl. B. B rox, Zeuge und Märtyrer. Untersuchungen zur frühchristlichen Zeugnis-Terminologie (Studien zum Alten und Neuen Testament, 5), München 1961, 166-171. 
Was die obengenannten Hipothesen betrifft, muss man zusammen mit anderen Verfassern behaupten, dass weder J. Geffcken, noch R. Reitzenstein, noch jemand anderer den Ursprung der christlichen Maryriumsidee aus den heidnischen Quellen bewiesen hat ${ }^{66}$. Eine überzeugende Antwort geben dagegen die einen Bezug auf das vorliegende Problem habenden Dokumente des Altertums. Man kann sie in zwei Gruppen teilen: die erste hat die Benennung "Heidnische Acta Martyrum" ${ }^{67}$ und zur zweiten gehören die "Unterredungen" von Epiktet ${ }^{68}$.

„Heidnische Acta Martyrum" beschreiben verschiedene in der Anwesenheit des Kaisers in Rom stattfindende Prozesse, in denen Angeklagte, denen man sich die Würde des Martyriums zu verleihen bemüht, die wegen der Gewaltakte gegen Juden verdächtigten Griechen aus Alexandrien waren ${ }^{69}$. Trotz dem täuschenden Anschein - sagt H. Musurillo sind sie nicht Màrtyrer im religiösen Sinn dieses Wortes, weil bei ihnen gepriesen werden: Ruhm der Stadt und Gesetze der Griechen, Liebe zum Vaterland, griechische Leben und Erziehung, um sie den Fehlern und zügellosen Sitten der Römer gegenüberzustellen ${ }^{70}$. „Heidnische Acta Martyrum" zeigen folglich ihre Helden als Führer einer gegenjüdischen politischen Partei mit einem hellenischen Geist. Der Unterschied also zwischen den christlichen Märtyrern, die für den den tiefsten Inhalt ihrer Überzeugung bildenen Glauben an Jesus Christus sterben und den hellenischen „Märtyrern” ist auffallend und klar. Das Studium der „Heidnischen Acta Martyrum" erlaubt höchstens - nach H. Musurillo - näher die Quellen dieser „Acta” und anderer Beschreibungen der Martyrien im Christientum $\mathrm{zu}$ bestimmen ${ }^{71}$. Es unterliegt heute keinem Zweifel, dass sie von dort ihre literarische Gattung schöpfen — und das ist alles; jeden anderen Einfluss muss man ablehnen ${ }^{72}$.

In den „Unterredungen” von Epiktet kann man zweifellos eine gewisse Ähnlichkeit zwischen einem.stoischen Philosophen und einem christlichen Märtyrer finden. Doch die Berührungspunkte - wie bemerkt mit Recht N. Brox - sind nicht beträchtlich. In seiner Auffassung könnte

${ }^{66} \mathrm{H}$. De 1 e ha ye, Sanctus. Essai sur le culte des saints dans l'antiquité (Subsidia hagiographica, 17), Bruxelles 1927, 96-100. - M. Viller, Martyre et perfection, in: Revue d'ascétique et de mystique, 6 (1925) 6. - Dör ri e, Märtyrer, 588. - B $\mathrm{rox}$, Zeuge und Märtyrer, 18; 152; 159-160; 175-179; 189-192.

${ }_{67}$ Acta Alexandrinorum (Bibliotheca scriptorum graecorum et romanorum teubneriana), ed. H. Musurillo, Lipsiae 1961. - Vgl. H. Deleh a ye, Les Passions des martyrs et les genres littéraires, Bruxelles 1921, 175-178.

${ }^{68} \mathrm{Ep}$ i c tète, Entretiens (Collection des Universités de France). Texte établi et traduit par J. Souilhé avec la collaboration de A. Jagu, I (Paris 1948); II (Paris 1949); III (Paris 1963); IV (Paris 1965).

69 Delehaye, Les passions des martyrs, 161-168. - Brox, Zeuge und Märtyrer, 175-176. Acta Alexandrinorum, VII-IX.

70 Acta Alexandrinorum, VIII.

71 Ebd., VIII.

$72 \mathrm{Brox}$, Zeuge und Märtyrer, 176. - Delehaye, Les Passions des martyrs, 168-182. 
man sie so kurzfassen. Hier und dort bilden die Zeugen einen besonderen Stand. Der Philosoph ist von Gott berufen und durch Ihn als würdig für seine besondere Funktion und Mission erkannt. Das erinnert auch etwas die christlichen Märtyrer. Auf der einen und auf der anderen Seite hat der Begriff des Zeugnisses einen religiösen Charakter. Die Auseinandersetzung mit dem Tyrannen ist bei beiden durch die Treue seiner Berufung verursacht. Dennoch die Motive, die den Zeugen zur Treue bewegen, sind völlig anders - und das ist entscheidend. Der Philosoph geht mit der stoischen als Wille des Zeus verstandenen Weisheit hervor. Der Märtyrer bekennt seinen Glauben an Jesus Christus und seine Verheissungen ${ }^{73}$. Der stoische Philosoph oder Zyniker ist weder irgendwo berufen der Wahrheit eines Faktums, mit dem er sich vertraut machte, ein Zeugnis zu geben, noch befindet sich im Dilemma: Doktrin oder Leben. Schlicht die Tugend ausübend und seine Taten mit seinem Willen in Ubereinstimmung bringend, ergibt er sich dem Vorhaben Gottes, wenn auch für den Preis des persönlichen Wohles oder Freiheit und auf diesem Weg wird er ein Vorbild, das Gott anderen Menschen zur Nachahmung vorschlagen kann ${ }^{74}$. Der philosophische durch Epiktet entworfene Martyriumsbegriff überschreitet also nicht die Rahmen der stoischen Philosophie. Und aus diesem Grund ist er in den Grenzen ihrer Idee zu verstehen ${ }^{\mathbf{7 5}}$.

In der Folgerung - abstrahierend selbstverständlich vom Judaismus, wo die ersten Grundrisse des Martyriumsbegriffes erschienen sind und vom Islam, in dem die die gemeinsamen historischen Wurzeln habende Martyriumsidee sich paralell mit der christlichen Idee entwickelt hat muss man sich darunter unterschreiben, was zu diesem Thema H. Dörrie bemerkt, und zwar, dass die nichtchristlichen Religionen keine der christlichen ähnliche Martyriumsidee gehabt haben und zwar aus zwei Gründen:

1) Keine heidnische Religion verlangte von ihren Anhängern absoluten Glauben, weil keine eine exclusive Bedeutung und ganze Hingabe beansprucht hat. Alle haben sich zu Mängel bekannt, waren damit einverstanden, was die anderen verkündet haben. Kein Lateiner kam auf den Gedanken, sein Leben zu kürzen, um die Anerkennung der griechischen Götter in Italien zu verhindern. Auch kein Kelte hätte einen Bluttropfen vergossen, um die Einrichtung griechisch-römischen Götter in Gallien $\mathrm{zu}$ verhindern ${ }^{76}$.

2) Die griechische Religiosität stützte sich auf ganz anderen Fund:menten als die christliche. Werke der Götter, ihre Existenz waren für

${ }^{73} \mathrm{Brox}$, Zeuge und Märtyrer, 190. - Vgl. ebd., 178-182; 189-192. - D e$1 \mathrm{e}$ h a e, Sanctus, $96-100$.

$74 \mathrm{D}$ el e ha y e, Sanctus, 98-99.

$75 \mathrm{Brox}$, Zeuge und Märtyrer, 181.

76 A $11 \mathrm{ard}$, Dix leçons sur le martyre, 2. 
sie verständlich. Schliesslich verlangte sie weder den Glauben, noch die Pflicht der Bezeugung. Daher der Tod der Helden des Altertums trug keine Kennzeichen der Bezeugung in sich, so wie die Zeugnisse der Christen. Nichts hat dort an die Bestätigung des unbeugsamen, tiefen und vernüftigen Faktums oder irgendwelcher Lehre erinnert ${ }^{\mathbf{7 7}}$.

All das, was das heidnische Alterum in die Idee des Martyriums, hineingebracht hat, und was man als weitere Vorbereitung für sie bezeichnen könnte, reduziert sich zur Achtung für den Tod und zur unbeugsamen Haltung inmitten der Widerwartigkeiten, was man in verschiedenen philosophischen Schulen gelehrt hat ${ }^{78}$.

\section{Jüdische Quellen}

Kann man in der Welt des Judentums die Martyriumsidee finden? Die Antwort auf diese Frage lautet positiv: Die Religion des Judentums hat ihre Märtyrer gehabt. Der erste war der zu eschatologischen Figuren gehörende Gottesknecht (Isai 42, 1-4; 49, 1-6; 50, 4-9; 52, 13-53, 12) ${ }^{79}$. Am meisten bekannte jüdische Märtyrer sind die Makkabäer. Man kann ihnen auch im späteren Judentum begegnen ${ }^{80}$. Wegen der Zahl der Märtyrer manche Autoren benennen sogar die jüdische Religion als eine Religion des Martyriums ${ }^{81}$.

Den jüdischen Einfluss auf die christliche Martyriumsidee kann man nicht bezweifeln. Dieses wird schon durch die Fortdauer beider Testamente verlangt. Schon die einfache Verwendung der Bücher des Alten Testamentes in den christlichen Gemeinden wäre genügend, abgesehen von den deutlichen Texten, um es zu zeigen, dass Beispiel der heidnischen Märtyrer nicht ohne Widerhall auf die christlichen Märtyrer geblieben ist $\mathbf{8 2}$. Wie schaut also die Linie aus, die die jüdische und christliche Martyriumsidee verbindet? Viele Reflexionen darüber ruft vor allem die Haltung

77 Ebd., 2.

78 Dörrie, Märtyrer, 587-588. Man muss auch den Einfluss des Kultes, den man im Altertum den Helden erwiesen hat, auf den christlichen Märtyrerkult auschliessen. T. Kla u s r, Christlicher Märtyrerkult, heidnischer Heroenkult und spätjüdische Heiligenverehrung. Neue Einsichten und neue Probleme, in: Arbelitsgemeinsichaft für Forsichung des Landes Nordrhein-Wesitfalen, Bd. 16 (KölnOpladen 1960), 35-37. - Vgl. H. Dele haye, Les origines du culte des martyrs, Bruxelles 21933, 404-417.

${ }^{79} \mathrm{~A}$. Gelin, Les origines bibliques de l'idée de martyre, in: Lumière et vie, 36 (1958) 123-124. - E. L o h m e y e r, L'idée du martyre dans le Judaisme et dans le Christianisme primitif, in: Revue d'histoire et de philosophie religieuses, 7 (1927) $317-319$.

${ }_{80} \mathrm{Surkau,}$ Martyrien in jüdischer und frühchristlicher Zeit, 9-82. - Brox, Zeuge und Märtyrer, 155-166.

${ }_{81}$ W. Bousiseit, H. Gressmann, Die Religion des Judentums im späthellenischen Zeitalter (Handbuch zum Neuen Testament, 21), Tübingen 1926, 374. ${ }^{82} \mathrm{H}$ o c e d e z, Le concept de martyr, 96. - Zum Gazen vgl. B a u m e is t e r, Die Anfänge der Theologie des Martyriums, 6-65. 
des Christentums, die dieses gegenüber den jüdischen Märtyrern eingenommen hat, vor. Ferner ist der genugtuende und verdienende Wert ihres Opfers zu berücksichtigen. Endlich soll die Gattung des durch die jüdische Märtyrer gegebenen Zeugnisses näher untersucht werden.

Es ist bekannt, dass die Urkirche jüdische Märtyrer, insbesondere die Makkabäer, als ihre eigene anerkannt hat; in Antiochien z. B. haben die Christen sogar das Grab der Makkabäer besetzt. Aus diesem Grund müssen die Juden in späterer Zeit auf dieses verzichten ${ }^{83}$. Es lohnt sich an dieser Stelle zu fragen, warum hat das die Kirche gemacht und welche Motive haben sie zu diesem Schritt bewegt. Wie hat man der Rechtfertigung wegen dieses wichtigen und ungewöhnlichen Faktum argumentiert? Dieses interessante Problem hat in der letzten Zeit T. W. Manson näher untersucht; vor allem hat er sich mit der Diskussion der Kirchenväter (Ignatius v. Antiochien, Irenäus, Cyprian, Origenes, Augustinus) zu diesem Thema vertraut gemacht. Seiner Meinung nach hat die patristische Überlieferung die Helden des Alten Testamentes als Zeugen Christi angesehen. In den Augen der Urkirche auch sie sind für Jesus gestorben ${ }^{84}$. Zweifellos mussten diese Anschauungen eine Beziehung der Abhängigkeit zwischen der jüdischen und christlichen Auffassung des Martyriums, im Märtyrerkult besonders sichtbar, schaffen ${ }^{85}$.

Ähnliche Erscheinung kann man auch anderswo feststellen, und zwar in der Beimessung dem Tode eines läuternden und verdienenden Wertes durch die jüdische Religion und durch das Christentum ${ }^{86}$. Ganz bestimmt war bei den Juden eine Meinungsverschiedenheit in dieser Frage, auch deswegen, da das Spätjudentum das Martyrium als Strafe für die Sünden versteht. Doch die Verbindung zwischen der Sünde und dem Martyrium war durch die Rabinen nicht gebilligt. Schliesslich waren alle einmütig was den grossen, moralischen Wert des Martyriums betrifft - insbesondere hat man ihm eine verdienende Kraft beigemessen. Die Märtyrer

${ }^{83}$ E. Lohse, Märtyrer und Gottesknecht. Untersuchungen zur urchristlichen Verkündigung vom Sühntod Jesu Christi (Forschungen zur Religion und Literatur des A. und. des N. Testaments, 64), Göttingen 21963, 72. - Ein anderes Beispiel der Aneingnung durch die Kirche der bei den Juden verehrten Gräber und Reliquien bringt ein in der letzten Zeit gefundene georgische Text über Jünglinge aus Babylonien: G. Garitte, L'invention des Trois Enfants de Babylone, in: Le Muséon, 72 (1959) $69-100$.

${ }_{84} \mathrm{~T}$. W. M a n s o n, Martyrs and Martyrdom, in: Bulletin of the John Rylands Library, 39 (1956-1957) 479; 483.

${ }^{85} \mathrm{~J}$. Jeremias, Heiligengräber in Jesu Umwelt (Mt 23, 29; 47). Eine Untersuchung zur Volksreligion der Zeit Jesu, Göttingen 1958. — K la u s e r, Christlicher Märtyrerkult, heidnischer Heroenkult und spätjüdische Heiligenverehrung, 34-35. - D. A. Schlatter, Der Märtyrer in den Anfängen der Kirche (Beiträge zur Förderung christlicher Theologie, 19), Gütersloh 1915, 27.

$80 \mathrm{~L}$ o h s e, Märtyrer und Gottesknecht, 67-78; 203-210. - E. Sta uffer, Die Theologie des Neuen Testaments, Güterloh 41948, 317. 
sollten für sich selbst und für das Volk die Gnade und den Segen Gottes verdienen ${ }^{87}$.

Die gleiche Idee kann man auch in der christlichen Martyrologie auffinden. Nach E. Peterson in der Urkirche wurden die Märtyrer als Besitzer der parrhesia gedacht. Sie war zweifache: eine auf der Erde und zweite im Himmel. Hier, auf der Erde, machte sich die parrhesia sichtbar in der würdigen und unbeugsamen Haltung der Märtyrer den Feinden des Glaubens gegenüber. Nach dem Tode dafür gehen die Märtyrer unmittelbar in den Himmel ein. Sie sehen Christus vor anderen Christen. Das was die Gläubigen erst erreichen werden, und das noch wahrscheinlich am jüngsten Tage, haben die Märtyrer ganz sicher sofort. Sogar mehr - sie gehören zu den „Freunden Gottes”. Sie dürfen Gott um alles bitten und faktisch beten sie für die Lebenden. Eben aus diesem Grund ist das Wort parrhesia bei den Griechen ein Zentralbegriff in der Lehre von der Fürbitte der Märtyrer, und danach der Heiligen überhaupt geworden ${ }^{88}$. Die gegenseitige Abhängigkeit ist also offenbar. Erblickte sie schon D. A. Schlatter ${ }^{89}$. In der Formulierung von E. Lohse wird sie am meisten sichtbar in dem, was schon gesagt wurde, d.h. dass im christlichen Glauben der Märtyrer nicht auf das jüngste Gericht in der Unterwelt wartet, weil auch die Juden an diese Wahrheit geglaubt haben. Das Christentum hat sie nur etwas modifiziert hinzufügend, dass der Tod das Verweilen und die Vereinigung mit Christus realisiert ${ }^{90}$. Damit wurde das Tor für den Einfluss jüdischer Auffassungen in die christliche Märtyrertheologie breit geöffnet ${ }^{91}$.

Das Problem des Zeugnisses, das die jüdischen Märtyrer gegeben haben, gehört vielleicht zu den am meisten diskutierten. Das Wesen dieses Problems besteht in der Antwort auf die Frage, ob ihr Leiden und Tod ein wahres für die Bestätigung des Glaubens gegebenes Zeugnis ist, oder ob diese einfach nicht die Treue dem alttestamentlichen Gesetz bedeuten. Es geht zwar darum, um zu prüfen, ob der christliche Martyriumsbegriff im minderen oder höheren Grad zu den gemordeten Juden angewandt wird, ob in dieser Hinsicht eine Übereinstimmung oder eine Divergenz der Ideen vorkommt. Was dieses betrifft sind die Autoren nicht einig. Die positive Antwort scheint sehr wahrscheinlich zu sein, deshalb muss man einige mehr charakteristische Ansichten auführen.

Die berühmteste und allgemein bekannte in dieser Sache ist die Ansicht von E. Lohmeyer. Er meint, dass sich im Martyriumsbegriff zwei

$87 \mathrm{Surkau,} \mathrm{Martyrien} \mathrm{in} \mathrm{jüdischer} \mathrm{und} \mathrm{frühchristlicher} \mathrm{Zeit,} \mathrm{138.} \mathrm{-} \mathrm{L} \mathrm{o} \mathrm{hs} \mathrm{e,}$ Märtyrer und Gottesknecht, 66-78.

${ }_{88}$ E. Peterson, Zur Bedeutungsgeschichte von Parrhesia (Sonderdruck aus der Reinhold-Seeberg-Festschrift), Leipzig 1929, 294. - Vgl. ebd. 292-293.

${ }^{89} \mathrm{~S} \mathrm{chlat}$ l e r, Der Märtyrer in den Anfängen der Kirche, 32.

${ }^{90} \mathrm{~L} / \mathrm{h}$ se, Märtyrer und Gottesknecht, 204.

91 Ebd., 205. - Vgl. ebd., 203-210. 
Gattungen der Ideen begegnen: die Idee, die den religiösen Wert des Leidens erkennt und die Idee, die die aktuelle Notwendigkeit des Bekenntnisses verkündet ${ }^{92}$. Diese Ideen eben scheinen sehr eng und direkt unlösbar bei Deutero-Jesaja, dem Schöpfer der Lehre über das Martyrium in der Religion des Judentums, verbunden zu sein. Denn Israel wegen seiner Gottes Erwählung ist ein Zeuge Gottes (Isai 43, 9); im Vergleich mit den anderen Völkern ist er ein verfolgtes Volk. Das Leiden Israels stellt Deutero-Jesaja dar als unverdientes und nur wegen der Gottes Erwählung, die aus ihm Gottes Zeugen macht, veranlasstes ${ }^{93}$. Daher die historischen und religiösen Geschicke machen aus dem auserwählten Volk einen Zeugen, so weit es leidet und soweit es zum Leiden verpflichtet ist, weil es ein Zeuge ist. Dieser notwendige Zusammenhang zwischen dem Zeugnis und dem Leiden ruht also auf der die Existenz der zwei im ununterbrochenen Konflikt bleibenden Welten annehmenden Metaphysik ${ }^{94}$ und die Idee des Zeugen fordert drei konstitutive Elemente der jüdischen Religion: Gott, Völker und Gemeinschaft des auserwählten Volkes ${ }^{95}$.

Mit der Zeit ist diese durch Deutero-Jesaja geschaffene Auffasung gewisser Modifikation, Materialisation erliegen ${ }^{96}$. Denn man hat begonnen als Zeugen nicht das Volk als solches, sondern bestimmte Individuen der Gerechten anzuerkennen. Sie haben für den Glauben manchmal gewaltige Verfolgungen gelitten. Bei ihnen impliziert auch der Glaube das Leiden und das Leiden bezeugt den Glauben. Utberdies ist die obige Vereinigung nur unter der Bedingung möglich, dass der Glaube ein öffentlich in der Welt angegriffenes Zeugnis zugleich dazu bestimmt, um die glorreiche und in keine Diskussion gestellte Existenz beim Ende der Welt zu erben, bedeutet. In dieser Weise das Schicksal des Märtyrers fasst kurz zusammen die Geschicke des Volkes ${ }^{97}$. Wie man sieht, das Martyrium nimmt hier einen eschatologischen Sinn an, weil es den Endtriumph sichert und gleichzeitig Gottes Schutz impliziert. Also dieselben drei mächtigen Elemente, die durch ihren gegenseitigen Zusammenhang so gut die jüdische Religion charakterisieren, bezeichnen ebenso gut die religiöse Bedeutung des Märtyrers ${ }^{98}$.

In der Verkündigung Jesu - nach E. Lohmeyer - befinden sich ganz deutlich alle konstitutive Bestandteile aus der jüdischen Auffassung des Martyriums. Man könnte sogar die These riskieren, dass der ursprüngliche Enthusiasmus der Christen gewissermassen sie geläutert und kondensiert

${ }^{29} \mathrm{~L}$ ohme yer, L'idée du martyre dans le Judaisme et dans le Christianisme primitif, 317; 326 .

93 Ebd., 318.

94 Ebd., 318.

95 Ebd., 319.

96 Ebd., 319.

97 Ebd., 320.

98 Ebd., 324. 
hat ${ }^{99}$. Christus lehrte, dass alle Gottes Gesandte sowohl die in der Vergangenheit lebende, als auch diejenigen, die erst kommen werden, waren oder werden verfolgt und getötet (Math $5,11-12 ; 23,34-35$; Hebr 11, 4; 12, 24). Die Welt bleibt prinzipiell in einer Opposition zu den Verkündigern des Wortes Gottes ${ }^{100}$. Der Märtyrer hat versicherten Gottes Schutz, der ihn im Bedarfsfalle inspiriert (Math 10, 18-20). Schliesslich zwei Schriften des Neuen Testamentes, und zwar der Brief des hl. Paulus an die Philipper und die Apokalypse des hl. Johannes Apostels, durch ihre Komposition, Struktur, Form und Inhalt, stellen sehr genau diese Martyriumsidee dar ${ }^{101}$. Auf diesem Weg wollte E. Lomeyer die christliche Martyriumsidee in der jüdischen Religion finden ${ }^{102}$.

Auch H. W. Surkau, anlässlich der die Quellen der Martyriumsidee betreffenden Polemik mit H. F. von Campenhausen, stellt sich die Frage bezüglich der jüdischen Texte; ob sie erlauben ihre Helden als Blutzeugen, als Märtyrer zu nennen ${ }^{103}$. Die Antwort ist positiv ausgefallen. Die Idee der Bezeugung vor der Welt Gottes Angelegenheiten befindet sich schon bei Deutero-Jesaja (Isai 43, 10; 53); auch in diesem Sinn sind die Makkabäer Zeugen genannt (4 Makk 12, 17; 16, 16) ${ }^{104}$. Obwohl es wahr ist, dass die Treue dem Gesetz sehr bedeutende Stelle in den jüdischen Erzählungen von den Märtyrern einnimmt, dennoch ist es zu betonen, dass sie das Gesetz verteidigend auch Gott ein Zeugnis gegeben haben. Sterbend bestätigt der Verfolgte vor den Feinden die Wirklichkeit des lebendigen Gottes, den sie missachten. Die Treue dem Gesetz bedeutet also seitens des Märtyrers das Bekenntnis Gottes, für den er vor der Welt das Lebenspofer darbringt ${ }^{105}$. Die Behauptung von H. F. von Campenhausen, die die Möglichkeit des Martyriums, ausserhalb der christlichen Religion verneint, geht nach $\mathrm{H}$. W. Surkau zu weit. Denn im Judaismus kann man etwas finden, was mit Recht als Blutzeugnis, d. h. Martyrium bezeichnet wird. Die Urkirche hat das nur dank den eingetragenen Modifikationen in die eigenen Ideen eingebaut 106.

$\begin{aligned} & { }^{99} \text { Ebd., } \\ & 100 \\ & 101 \\ & 101 \\ & \text { Ebd., }\end{aligned} 325$.

102 Die Hypothese von E. Lohmeyer ist scharf kristisiert. E. Hocedez hat ihr vorgeworfen, dass sie keine Grundlage in den biblischen Texten hat: „Toute cette synthèse de $\mathrm{E}$. Lohmeyer, si belle et si élevée, nous apparaït comme une vue de l'esprit, dans le recul de l'histoire, non comme une vue des contemporains; c'est une explication, très vraie sans doute, du rôle d'Israel, mais cette explication n'est pas exprimée dans les textes, rien ne suggère qu'elle fut aperçue par les Juifs: elle est le fruit de la réflexion phillosophique de l'auteur", Le concept de martyr, 9899. - Vgl. ebd. 80-84; 96-99. - Nach H. F. v. Campenhausen, E. Lohmeyer ,vermischt weittgehend alle Uniterschliede, die zwischen judisichen, früh- und spätsichristlichen 'Martyrien' bestehen', Die Idee des Martyriums in der alten Kirche, 3, Anm. 3.

${ }_{103} \mathrm{~S}$ urka u, Martyrien in jüdischer und frühchristlicher Zeit, 135-139.

104 Ebd., 136.

105 Ebd., 137.

10 Ebd., 139. - Kritische Bemerkungen bezüglich der Theorie von H. W. Surkau 
Ähnliche Ansicht äussert T. W. Manson. Er meint, dass Leiden und Tod für die Religion dem Judaismus bekannt waren ${ }^{107}$. In erster Reihe sind dort die Propheten als Märtyrer zu erkennen. Sie waren Zeugen par excellence, d. h. Augen- und Ohrenzeugen im vollen Sinn dieses Wortes, weil sie von den Räten Jahwe (the Council of Yahweh) gesehenen und gehörten Sachen sprachen. Eben die Propheten, als sie vor Israel die Absichten Gottes bezeugt haben, waren verfolgt und sogar getötet ${ }^{108}$. Ferner das ganze Volk Israel war als Zeuge Gottes erkannt. Durch seine wechselnde historische Existenz bestätigte es die Wirklichkeit und die Nachsehbarkeit des Prophetenzeugnisses, dessen Empfänger es war ${ }^{109}$. Schliessiich gibt es keinen wesentlichen Unterschied, was das Martyrium betrifft, zwischen der jüdischen und christlichen Religion ${ }^{110}$.

In demselben Sinn, d.h. der Berührungspunkte zwischen dem Alten Testament und der Kirche bezüglich der Martyriumsfrage äussert sich auch G. von Rad. Er sieht z. B. den Zusammenhang zwischen dem Leiden und der Bezeugung bei den Propheten Daniel und Jeremias ${ }^{111}$.

All das, was von den Zusammenhängen zwischen der jüdischen und christlichen Martyriumsidee gesagt wurde, summieren ziemlich ausführlich die Bemerkungen von A. Gelin. Nun, der Hebräerbrief (11,33-38) zitierend global für die Propheten reservierte Vorfolgungen gibt die jüdische Tradition betreffs des Martyriums. Die Martyriumsproblematik hat ihren Anfang bei den Propheten genommen, dann wurde sie durch Jesus, den hl. Stephan und den hl. Paulus akzeptiert und breit entwickelt (Math 23, 31; Apg 7, 52; 1 Thes 2, 15). Hier und dort kommen dieselben Ideen vor. Es fällt dafür auf in dieser Etappe das Fehlen der Benennung betreffs des Martyriumsterminus, der durch die Christen später (2. Jhdt) ausgearbeitet wurde ${ }^{112}$.

kann man in der Rezension des Werkes von Surkau, Martyrien in jüdischer und frühchristlicher Zeit, finden, die P. Devos geschrieben hat, in: „Analecta Bollandiana", 57 (1939) 136-138. - Brox, Zeuge und Märtyrer, 143-143; 146; $150-153 ; 164$.

$107 \mathrm{M}$ a n s o n, Martyrs and Martyrdom. 464.

108 Ebd., 475. - Vgl. ebd. 466; 469;472; 473-474; 483-484. - Nach H. J. S choeps die Behauptungen von dem Märtyrertod der Propheten meistens stammen aus den Apokryphen und deswegen nicht immer mit der Wahrheit übereinstimmen: Aus Frühchristlicher Zeit. Religionsgeschichtliche Untersuchungen, Tübingen $1950,142$.

109 M a n s o n, Martyrs and Martyrdom, 466; 483.

110 Auf Mängel und Lücke der Auffassung von T. W. Manson zeigt B rox, Zeuge und Märtyrer, 145.

111 G. von Rad, Theologie des Alten Testaments, Bd II: Die Theologie der prophetischen Überlieferungen Israels, München 1960, $128 \mathrm{f}$.

112 Gelin, Les origines bibliques de l'idée de martyre, 128-129. - Eine Gegenopinion, d.h. eine den Zusammenhang zwischen der Bezeugung und dem Leiden, bzw. Tod, bei den jüdischen „Märtyrern" ausschliessende Opinion repräsentieren folgende Autoren: A 11 a r d, Dix leçons sur le martyre, 2-3. - C a m p e $\mathrm{n}$ a u s e n, Die Idee des Martyriums in der alten Kirche, 2-5. - Strathman $\mathrm{n}$, Martys, 491. - B r ox, Zeuge und Märtyrer, 172-173. 


\section{Chistozentrischer Charakter}

Es ist noch eine Frage zu beantworten: was bringt die christliche Martyriumsidee in das durch die treu dem Gesetz jüdischen Märtyrer gegebene Blutzeugnis hinein.

Die Eigenartigkeit der christlichen Martyriumsauffassung drückt sich vor allem in ihrem christozentrischen Charakter aus ${ }^{113}$. Es wurde schon oben gesagt, dass den Gegenstand des Zeugnisses bei den christlichen Märtyrern die Person Christi und sein Werk bildet: sie sterben, um ihre Wahrheit zu bestätigen. Der christozentrische Charakter der christlichen Martyriumsauffassung tritt also vor allem in der sehr engen, tiefen und persönlichen Beziehung, die zwischen Christus und dem Märtyrer besteht, hervor. Diese besondere Beziehung kann man in zwei Worten fassen: Nachfolge und Vereinigung.

Das ganze Christentum ist von dem Gedanken erfüllt, dass das Martyrium die volkommenste Art der Nachfolge Christi ist. Die Nachfolge ist zum Grundfaktor, zur führenden Idee des Martyriums in christlicher Sicht geworden, was viele Texte der hl. Schrift bestätigen (Joh 13, 36; 21, 18 ff; Eph 5, 2; 1 Petr 4, 1-19; Apok 14, 3 f.). So hat man in den ersten drei Jahrhunderten, also während der grössten Verfolgungen der Kirche gelehrt, aber auch in der späteren Zeit hat man nicht aufgehört das Martyrium als vollkommenste Nachfolge Christi zu erkennen ${ }^{114}$. Sogar die in der Zeit der Reformation getrennten Gemeinschaften nahmen es ohne Vorbehalt an ${ }^{\mathbf{1 1 5}}$. Selbstverständlich, um besser in diesen Gedanken eindringen $\mathrm{zu}$ können, muss man ihn im Kontekst der Lehre von der Nachfolge Christi überhaupt betrachten ${ }^{\mathbf{1 1 6}}$.

Der Christ ist ein Jünger - bemerkt M. Viller - dessen Pflicht sich nach Jesus, seinem Meister zu bilden bleibt; die Nachfolge Christi soll sein ganzes Leben umfassen. Doch in den Zeiten der Vorfolgungen wird sie eine besondere Beziehung mit dem leidenden Jesus haben. Denn in den Verfolgungen die Passion und der Tod Christi mehr die Aufmerksamk^it der Christen fesseln ${ }^{\mathbf{1 1 7}}$. Der Tod des Christen wegen des Zeugnisge$1 \quad$ Iür Christus bildet den Höhepunkt seiner Nachfolge und deswegen -

${ }^{113}$ L. B ou yer, La spiritualité du Nouveau Testament et des Pères (Histoire de la spiritualité chrétienne, 1), Paris 1960, 242. - Die genaue Besprechung der Texte vgl. Ba ume is ter, Die Anfänge der Theologie des Martyriums, 66-306.

$114 \mathrm{~J} . \quad \mathrm{M}$ a do z, El amor a Jesucristo en la Iglesia de los mártires, in: Estudios eclesiasticos, 12 (1923) 331-334. - Vgl. Ku biś, La théologie du martyre au vingtième siècle, 79-80, Anm. 114.

${ }_{115}$ Stauffer, Märtyrertheologie und Täuferbewegung, 564; 570-573.

116 Vgl. zwei Aufsätze unter demselben Titel: Nachfolge Christi - mit der betreffenden Literatur, in: Die Religion in Geschichte und Gegenwart, $4\left({ }^{3} 1960\right)$ 1286-1293 und Lexikon für Theologie und Kirche, 7 (21962) 758-764. Sie sind durch sechs verschiedene Autoren geschrieben: E. Lohse, E. Kähler, N. H. See und A. Schulz, R. Hoffmann, E. Iserloich.

${ }^{117}$ Viller, Martyre et perfection, 6-7. 
sagt mit Recht E. Lohmeyer - in der Verkündigung Christi sein Leiden und Tod so grosse Bedeutung haben und als vollkommenstes Vorbild des christlichen Martyriums beschrieben wurden ${ }^{118}$. Jesus Christus, „der treue und zuverlässige Zeuge" (Apok 1, 5; 3, 14) ist ein Urtypus des Märtyrers ${ }^{119}$. In den Augen der Gläubigen steht der Märtyrer wegen der überstandenen Qualen neben Christus, dem ersten Märtyrer, er folgt Ihm nach und ist sein Wetteifer ${ }^{120}$. Leidend zusammen mit seinem Meister bildet er in sich seine Leiden und trägt seine Malzeichen. Es ist die tiefste Verwirklichung der Lebensgemeischaft mit Ihm, es ist auch die Fülle der Liebe ${ }^{121}$.

Diese ungewöhnlich nahe Beziehung zwischen dem Opfer Christi und dem des Märtyrers hat vielleicht ihren vollsten Ausdruck im Brauch der Eucharistiefeier am Jahrestag des Todes oder der Übertragung der Reliquien an den Märtyrergräben gefunden; in dieser Weise stellt die Liturgie angeblich Mysterium Christi und Mysterium des Märtyrers nebeneinander, sie will die gegenseitige Konpenetration dieser zwei übernatürlichen Wirklichkeiten betonen ${ }^{122}$. Nach O. Casel die zwischen ihnen bestende Beziehung kann man mit der Relation vergleichen, die zwischen dem Tode Christi und dem Tod der Märtyrer besteht. Das Märtyrermysterium ist Frucht und Teil des Mysteriums Christi. Sie fliessen zusammen und im Grunde sind eines. Die Märtyrerverehrung hat kein zweites vom Christusmysterium unabhängiges Mysterium geschaffen, sondern das Letzte vielmehr nur ausgebaut und angewandt wurde ${ }^{123}$. Mit anderen Worten die am Grab des Märtyrers zelebrierte Messe weist darauf hin, dass sein Tod an der Gröse des Opfers Christi Anteil hat ${ }^{\mathbf{1 2 4}}$. Den vollen Inhalt dieser Wahrheit drückte lapidar vor der Reform ein altes liturgisches Gebet, und zwar das Gabengebet vom Donnerstag in der dritten Woche der Fastenzeit: „Herr, wir bringen bei der Feier des kostbaren Todes Deiner Gerechten jenes Opfer dar, von dem jedes Martyrium seinen Ausgang nahm". Also mit Recht schreibt O. Casel, dass jedes Martyrium und folglich jedes Mysterium des Mätyrers das Opfer

${ }^{118}$ L o h meyer, L'idée du martyre dans le Judaisme et dans le Christianisme primitif, 326. - Vgl. K r a n i c h, Ist Kriegertod Märtyrertod?, 3; 5; 17. - K. H. $\mathrm{S}$ chelke, Die Passion Jesu in der Verkündigung des Neuen Testaments. Ein Beitrag zur Formgeschichte des Neuen Testaments, Heidelberg 1949, 222-230.

119 S t a uffer, Die Theologie des Neuen Testaments, 164-167. $-496$.

120 Corssen, Begriff und Wesen des Märtyrers in der alten Kirche, 494

${ }_{121} \mathrm{Schmaus,}$ Katholische Dogmatik, Bd. IV/1, $155 ; 176 ; 395 ; 476 .-\mathrm{M}$. Pellegrino, L'imitation du Christ dans les Actes des martyrs, in: La vie spirituelle, 38 (1958) 38-54.

${ }_{122}$ B. de Gaffier, Réflexions sur les origines du culte des martyrs, in: La Maison-Dieu, 52 (1957) 30-34.

${ }_{123} \mathrm{O}$. Casel, Mysterium und Martyrium in den römischen Sakramentarien, in: Jahrbuch für Liturgiewissenschaft, 2 (1922) 29.

${ }_{124} \mathrm{De} \mathrm{Gaffier,}$ Réflexions sur les origines du culte des martyrs, 31. 
Christi, das liturgisch genommen die Messe, Mysterium Christi ist, als Quelle haben ${ }^{125}$.

Von der Nachfolge Christi zur Vereinigung mit Ihm, wie haben wir gesehen, ist nur ein kleiner Schritt. Das Martyrium galt immer als das sicherste Mittel zur Vereinigung mit Christus ${ }^{126}$, und das Thema der Nachfolge erreicht seinen vollen Sinn erst in der Hoffnung des „Gelangens zu Christus", des ,in Christus gefunden werden" ${ }^{127}$. Es geht hier um die Vereinigung des Märtyrers mit Christus im ganz besonderen Sinn. Auf der Erde übersteigt sie jede andere Verbindung, welche die Glaübigen mit Jesus haben können. Sie ist so tief, dass sie dem Märtyrer eine besondere Anwesenheit des Meisters bringt und ihn in Widerständen bekräftigt: Jesus Christus lebt und wirkt mit dem Märtyrer und im Märtyrer 128. Am deutlichsten drücken den allgemeinen Glauben der Kirche in dieser Hinsicht die Worte der hl. Felicitas aus. Die sich im Gefängnis befindende und Geburtswehen leidende Heilige, fragte der Gefängnisschutzmann, was sie den Tieren zur Qual geworfen machen wird, wenn sie schon jetzt so leidet. „Jetzt - lautete die Antwort - leide ich selbst, aber dort jemand anderer in mir sein wird, der für mich leiden wird, weil dann auch ich für Ihn leiden werde" ${ }^{129}$. Eben dieser Glaube der Kirche bewirkte, dass mit der Zeit das Wort Christophoros für die Märtyrer ein ehrenvoller Titel geworden ist. Trotz der Unterschiede in der Auslegung im Westen und im Osten, (Christophoroi - Christusträger) (Christophoros - von Christus erfüllt, von Logos begabt), bedeutete dieses Wort vor allem die befestigende und siegende Anwesenheit Christi in den Märtyrern ${ }^{130}$. Viele von ihnen gingen wirklich zur Qual mit Freude hassend den Tod; gequält empfanden sogar keinen Schmerz, ihr Tod wurde von Visionen, Extase und Wundern begleitet. Denn hat ihnen Geist Gottes und Christi nicht nur Beistand geleistet - bemerkt M. Lods - sondern er wohnte auch in ihnen, damit sie über eigene menschliche Schwäche Angst und unausprechliche Schmerzen triumphieren können ${ }^{131}$. Die Ein29.

${ }_{125} \mathrm{Case} 1$, Mysterium und Martyrium in den römischen Sakramentarien,

$126 \mathrm{Viller-R}$ ahner, Aszese und Mystik in der Väterzeit, 33. - Vgl. Vi1le r, Martyre et perfection, 13-17.

${ }^{127}$ B o u y er, La spiritualité du Nouveau Testament et des Pères, 250-256.

$128 \mathrm{~V}$ iller, Les martyrs et l'Esprit, 544-545. Ders., Martyre et perfection, 13-17. - Viller-Rahner, Aszese und Mystik in der Väterzeit, 33-36. M. Lot-Borodin e, Le martyre comme témignage de l'amour de Dieu, d'après Nicolas Cabasilas, in: Irénikon, 27 (1957) 157-159; 161-163. - S to l z, L'ascèse chrétienne, 130-131. - Lods, Confesseurs et martyrs, 18-22.

129 Passio SS. Perpetuae et Felicitatis 15, 5-6: hrsg. C.I.M.I. van Beek, Passio sanctarum Perpetuae et Felicitatis, I (Noviomagi 1936), 36; 38.

130 F. J. Dölg er, Christophoros als Ehrentitel für Märtyrer und Heilige im christlichen Altertum, in: Antike und Christentum, 4 (1934) 75-76.

${ }^{131}$ L o d s, Confesseurs et martyrs, 333. - Vgl. ebd., 29-32. - H. A c h elis, Das Christentum in den ersten drei Jahrhunderten, I (Leipzig 1912), 295; II (Leipzig 1912), 444-445. 
heit des Märtyrers mit Christus bricht nicht sogar der Tod. Der Himmel, der für viele und nach manchen Autoren für alle lang unzugänglich bleibt nur für die Märtyrer öffnet sich ohne Erwartung. Sterbend erreichen sie sofort den Herrn ${ }^{132}$.

Die oben geäusserten Gedanken fasst gut L. Bouyer zusammen bemerkend, dass das Martyrium zu den grössten charismatischen Phänomenen der Urkirche gehört. Die Anhäufung verschiedener Charismen rund um das Martyrium soll nicht vergessen lassen, dass dieses selbst das grösste Charisma ist. Das ist es darum, weil es die Vereinigung mit Christus-Gott und die Fülle der vollkommenen Liebe verwirklicht ${ }^{133}$.

\section{MARTYRIUM UND KIRCHE}

$\mathrm{Zu}$ diesen Erwägungen sind noch als Folgerung einige Bemerkungen über den ekklesiologischen Sinn des Martyriums hinzuzufügen, weil dieses in der Struktur der Kirche eine unersetzliche und wesentliche Stelle einnimmt.

Die Verbindugen zwischen dem Märtyrer und der Kirche sind vielfach. Der Märtyrer bekennt seine Zugehörigkeit zur Gemeinschaft der Gläubigen, betet und leidet für die Kirche, muntert seine Mitbekenner zur Ausdauer in der Gefahr durch das Wort und besonders durch das Beispiel auf. Kirche ihrerseits bereitet die Gläubigen zur Ausdauer vor verkündend das Wort Gottes und spendend die hl. Sakramente. In dieser Weise erlangen die Märtyrer erforderliche zum Kampf Kräfte. Im Bedarfsfalle sichert die Kirche dem Märtyrer, wenn es möglich ist, Schutz bis zur letzten Probe, bestattet fromm seine sterbliche Hülle, schreibt seinen Namen in ihren Kalendern ein und erweist ihm den religiösen Kult ${ }^{134}$.

Man soll doch noch tiefer ausserhalb dieser „phänomenologischen” Beschreibung streben, um die Relation zwischen dem Märtyrer und der Kirche zu bezeichnen. Nach E. Peterson ${ }^{\mathbf{1 3 5}}$, die bevorrechtete Situation des Martyriums in der Kirche war Gegenstand der Verkündigung in der Urkatechese und wird schon in den Schriften des Neuen Testamentes sichtbar ${ }^{136}$. Seine Erwägungen gründet er in diesem Fall auf der den

132 J. P. Kirsch, Die Lehre von der Gemeinschaft der Heiligen im christlichen Altertum. Eine dogmengeschichtliche Studie (Forschungen zur christlichen Literatur und Dogmengeschichte, 1) Mainz 1900, 68-74. - Katten bus ch, Der Märtyrertitel, 116-118. - Achelis, Das Christentum in den ersten drei Jahrhunderten, $11 ; 349-350 ; 441$. - L o t-B or o din e, Le martyre de l'amour, d'après Nicolas Cabasilas, 163-165.

${ }^{133}$ B o u yer, La spiritualité du Nouveau Testament et des Pères, 254; 256.

$134 \mathrm{M}$. Pellegrino, Le sens ecclésial du martyre, in: Revue des sciences religieuses. 35 (1961) 152. - Vgl. ebd., 156-174.

${ }_{135}$ E. Peterson, Zeuge der Wahrheit (Der Märtyrer und die Kirche), in: Ders. Theologische Traktate, München 1951, 165-183.

136 Ebd., 168 und Anm. 3, 220. 
Aposteln vor ihrem Ausgehen zur Mission gegebenen Belehrung Jesu Christi (Math 10) ${ }^{\mathbf{1 3 7}}$. Zwei von seinen Folgerungen sind besonders bemerkenswert.

Nach Peterson setzt das Martyrium zuerst eine besondere Berufung voraus, es ist ein Charisma ${ }^{138}$, d.h., eine geistige Gabe ${ }^{139}$, weil die Stellung des Märtyrers in der Kirche eine Stellung des Menschen ist, der ein besonderes Charisma empfangen hat ${ }^{\mathbf{1 4 0}}$. Es ist eine besondere Gnade, weil kein Mensch dieses aus eigener Intitative und Kräften erreichen kann ${ }^{141}$.

Als Charisma das Martyrium muss nicht mit einer Funktion in der Kirche verbunden werden. Amt und Charisma waren nur bei den Aposteln vereinigt; es war eine Ausnahmestellung. Schliesslich muss man den Begriff des Martyriums von der Person des Apostels als solchen trennen, obwohl die Apostel auch Märtyrer waren ${ }^{142}$. Diese These wird zweifach begründet. Einerseits der Nachfolger der Apostel im ekklesiologischen Sinn dieses Wortes ist nicht ihr Nachfolger im Leiden, andererseits apostolische Leiden können jemanden treffen, der rechtlich genommen kein Nachfolger der Apostel ist 143. Mit ganzer Demut muss man hier feststellen, dass die Nachfolger der zwölf Apostel sind keine Apostel mehr und dass das Martyrium in der Kirche als eine abgesonderte Kategorie von Menschen notwendig ist, wenn die Kirche nicht nur in der Verkündigung, sondern auch in ihrem Leben beweisen soll, dass sie den Anteil an apostolischen Charismen, deren Bestandteil das Leiden und Martyrium der Apostel waren, fortsetzt ${ }^{144}$.

Ferner meint Peterson, dass das Martyrium organisch zum Wesen der Kirche gehört, d.h. dass dieses mit einer absoluten Notwendigkeit als Bestandteil in ihren Begriff eingeht 145. Was bedeutet das? Verfolgungen in der Kirche sind nicht etwas zufälliges und gelegentliches, sie sind nicht durch Missverständnis oder Irrtum verursacht, d.h. man kann sie nicht ausschliesslich der menschlichen Perversität und Boshaftigkeit zuschreiben. Christus selbst hat seiner Kirche Hass und Leiden seitens der Juden und Heiden vorausgesagt. Die Worte Jesu: „Musste nicht der Messias all das erleiden und so in seine Herrlichkeit eintreten" (Luk 24, 26) herrschen über der ganzen Kirchengeschichte. Und sie wird so lang

137 Ebd., 168-172.

138 Ebd., 181.

${ }^{139} \mathrm{Ch}$. Journet, L’Église du Verbe incarné. Essai de théologie spéculative. II. Sa structure interne et son unité catholique, Paris 1962, 319, Anm. 3.

${ }^{140}$ Peters on, Zeuge der Wahrheit (Der Märtyrer und die Kirche), 175.

141 Ebd. 173.

142 Ebd., 175.

143 Ebd., 173.

144 Ebd., 174. - Vgl. O. Miche 1, Zum Märtyrer-Problem, in: Theologische Blätter, 17 (1938) 88.

${ }^{145}$ Peters on, Zeuge der Wahrheit (Der Märtyrer und die Kirche), 177. 
Märtyrer haben, wie lang das Evangelium der Welt verkündet wird, d.h. bis zum Ende der Welt.

Es ist offenbar, dass eine Epoche der Kirche weniger Märtyrerepoche war, andere mehr, aber die Behauptung, dass es Momente in ihrer Geschichte ohne Märtyrer waren, wäre gleichfalls mit der Verneigung der Existenz der Kirche in diesen Zeiten überhaupt ${ }^{146}$. Das Zeugnis des Wortes ist mit dem Zeugnis des Leidens nicht nur dank einem einfachen Zusammentreffen von Umständen verbunden, sondern eine Wirklichkeit bildet, deren Existenz Christus selbst vorausgesagt hat ${ }^{147}$. Und die Verfolger? Wer sind sie? Was für ein Schicksal erwartet sie? Es sind nicht Menschen allgemein, abstrakt genommen, sondern konkrete Menschen, die in der Welt als Juden oder Heiden leben ${ }^{148}$. Sie sind Feinde des Evangeliums geworden, damit Gott sich in seiner Barmherzigkeit einer und anderer erbarmt ${ }^{149}$.

Es sei uns erlaubt noch eine Bemerkung von Peterson anzuführen; diesmal bezüglich der zur Ehre der Märtyrer in Rom vom Papst Damasus I. komponierten Gräberinschriften ${ }^{150}$. Über die Verfolgungen der Kirche kann man auf diesen rührende Worte lesen. „Als der Schwert das Mutterherz durchbohrt hat". Mutter Christi leidet mit den Märtyrern, die für den Leib Christi, die Kirche, in ihrem irdischen Leben das Mass seiner Leiden erfüllen (vgl. Kol 1, 24), weil Christus selbst in ihnen leidet. Sei aus diesem Grund der Titel „Königin der Märtyrer” nicht mit Recht Mariä, der Mutter Christi zugeschrieben?

146 Ebd., 176, 177.

147 Pellegrino, Le sens ecclésial du martyre, 154.

${ }^{148}$ Peterson, Zeuge der Wahrheit (Der Märtyrer und die Kirche), 177.

149 Ebd., 178.

150 Ebd., 183. 